\title{
Respon tanaman hanjeli (Coix lacryma-jobi L.) akibat kombinasi jarak tanam dengan dosis pupuk organik cair di kecamatan Rancakalong
}

\section{Response of job's tears (Coix lacryma-jobi L.) due to the combination of plant spacing with doses of liquid organic fertilizer at rancakalong}

Diterima : 15 November 2016/Disetujui : 15 Desember 2016 / Dipublikasikan : 30 Desember 2016

CDepartment of Crop Science, Padjadjaran University

\begin{abstract}
Population growth causes increases of food needs. One of alternative solution is food diversification program. Job's tears is one of the alternative food crops, but farmers are not steeped in this crop cultivation techniques, especially fertilization. Therefore to improve growth and yield job's tears with combinations of spacing and doses of liquid organic fertilizer. This study aimed to obtain a spacing combinations and doses of liquid organic fertilizer to increase crop yields job's tears. The experiment was conducted at Desa Pasir Biru, Kecamatan Rancakalong,Kabupaten Sumedang from December 2015 to May 2016. Hanjeli seed that used in this research is Job's tears Pulut accession number 37. The experimental design used was randomized complete block design (RCBD), which consists of 9 treatments. Spacing used was $50 \times 50 \mathrm{~cm}, 75 \times 50 \mathrm{~cm}$ and $100 \times 50 \mathrm{~cm}$. Dose of liquid organic fertilizer used are 0,15 and $30 \mathrm{~L} / \mathrm{ha}$. The experimental results showed that the combination spacing of $50 \times 50 \mathrm{~cm}+30$ L ha-1 liquid organic fertilizer is a better treatment that can boost crops yield components and yield in hanjeli.
\end{abstract}

Keywords: Coix lacryma-jobi L. · Liquid organic fertilizer · Plant spacing

Sari Pertambahan jumlah penduduk yang sangat besar menyebabkan kebutuhan pangan meningkat.Salah satu alternatif yang dapat dijadikan solusi adalah program diversifikasi pangan.Hanjeli adalah salah satu tanaman pangan alternatif, namun petani belum mendalami teknik budidaya tanaman ini

\begin{tabular}{l}
\hline Dikomunikasikan oleh Tati Nurmala \\
\hline${\text { Wahyudin, A. }{ }^{1} \cdot \text { Ruminta }^{1} \cdot \text { Y. Yuwariah }}^{1} \cdot$ M. Fauzi \\
\\
${ }^{1}$ Dosen Fakultas Pertanian,Universitas Padjadjaran \\
Jl.Raya Jatinangor Km .21 Jatinangor, Sumedang45363 \\
${ }^{2}$ Alumni Program Studi Agroteknologi,Fakultas \\
Pertanian,Universitas Padjadjaran
\end{tabular}

terutama pemupukan.Oleh karena itu dilakukan suatu upaya untuk meningkatkan pertumbuhan dan hasil hanjeli dengan kombinasi jarak tanam dengan dosis pupuk organik cair.Penelitian ini bertujuan untuk memperoleh kombinasi jarak tanam dengan dosis pupuk organik cair untuk meningkatkan hasil tanaman hanjeli. Percobaan dilaksanakan di Desa Pasir Biru, Kecamatan Rancakalong, Kabupaten Sumedang pada bulan Desember 2015 sampai dengan Mei 2016. Bibit Hanjeli yang dipergunakan adalah Hanjeli Pulut aksesi 37.Rancangan percobaan yang digunakan adalah Rancangan Acak Kelompok (RAK) yang terdiri dari 9 perlakuan. Jarak tanam yang dipergunakan adalah $50 \times 50 \mathrm{~cm}, 75 \times 50 \mathrm{~cm}$, dan $100 \times 50 \mathrm{~cm}$. Dosis pupuk organik cair yang digunakan adalah 15 dan $30 \mathrm{~L} / \mathrm{ha}$. Hasil percobaan menunjukkan bahwa kombinasi jarak tanam $50 \mathrm{~cm} \times 50 \mathrm{~cm}+30 \mathrm{~L} \mathrm{ha}^{-1}$ pupuk organik cair merupakan perlakuan yang dapat menigkatkan komponen hasil dan hasil pada tanaman hanjeli.

Kata kunci: Coix lacryma-jobi L. · Pupuk organik cair · Jarak tanam

\section{Pendahuluan}

Hanjeli adalah tanaman yang memiliki banyak manfaat. Hampir semua bagian tanaman hanjeli seperti biji, daun, batang, dan akar dapat dimanfaatkan. Biji hanjeli dapat digunakan sebagai bahan pangan, sebagai sumber karbohidrat dengan nilai gizi cukup memadai sekitar $76,40 \%$ karbohidrat, 7,90 \% lemak dan $14,10 \%$ protein (Nurmala dan Irwan, 2007), sehingga hanjeli bisa dijadikan bahan pangan alternatif pengganti beras.

Kandungan nutrisi hanjeli yang cukup tinggi saat ini masih belum dapat dimanfaatkan secara optimal. Hal ini dikarenakan pengem- 
bangan hanjeli sendiri belum maksimal. Para petani masih setengah hati untuk menanam hanjeli karena permintaan hanjeli belum setinggi sebagaimana produk serealia yang lain seperti beras, jagung gandum dan kacang-kacangan. Pemanfaatan hanjeli oleh petani masih terkendala dengan fasilitas yang diperlukan seperti mesin pemecah biji dan peralatan pengolahan pasca panen lainnya. Perkembangan dan pertumbuhan tanaman hanjeli ditentukan oleh faktor lingkungan. Faktor lingkungan yang berpengaruh antara lain populasi tanaman dan tersedianya unsur hara bagi tanaman.

Tajuk tanaman dan perakaran menentukan jarak tanam. Hal ini berkaitan dengan penyerapan sinar matahari dan unsur hara oleh tanaman, sehingga dapat mempengaruhi per-tumbuhan dan produksi tanaman. Tanaman dengan jarak yang lebar mendapatkan sinar matahari dan unsur hara yang cukup karena persaingan antar tanaman yang kecil, sedangkan tanaman dengan jarak tanam yang sempit menimbulkan adanya persaingan antar tanaman dalam hal cahaya, unsur hara, dan air. Dalam penelitian Pedersen dan Lauer (2003) menyatakan bahwa jarak tanam yang lebih sempit menurunkan produksi hingga $11 \%$ dibandingkan jarak tanam yang lebih lebar pada tanaman jagung.

Penyebab perbedaan hasil dari pengaruh jarak tanam terhadap pertumbuhan dan produksi hanjeli belum diketahui secara pasti. Menurut Thomson dan Kelly (1987) tujuan pengaturan jarak tanam pada dasarnya untuk memberikan kesempatan tanaman tumbuh dengan baik tanpa mengalami persaingan dalam pengambilan air, unsur hara dan cahaya matahari. Semakin banyak jumlah tanaman per satuan luas menyebabkan presentase cahaya yang diterima oleh bagian tanaman yang lebih rendah menjadi lebih sedikit, karena adanya penghalang untuk masuknya cahaya oleh daun-daun di atasnya.

Godlsworthy dan Fisher (1992) menyatakan pada kerapatan yang tinggi, ukuran tanaman sangat berkurang dan kedalaman perakaran mungkin tidak dapat tercapai.Hal ini dapat menyebabkan tidak terserapnya unsur hara yang berada jauh di bawah jangkauan daya serap akar. Penyebaran tanah Inceptisol yang cukup luas di Indonesia terutama di Sumatera dan Sulawesi dan terdapat pula di Kalimantan Tengah dan Selatan, Kepulauan Maluku, Minahasa, Jawa Barat, Jawa Tengah, Jawa Timur dan Bali walaupun tidak begitu luas.

Agar dapat tumbuh dengan baik, tanaman memerlukan berbagai macam unsur hara yang biasanya didapatkan dari tanah, namun karena unsur hara yang berada di dalam tanah berjumlah sangat minim, terutaman untuk unsur hara yang sering diolah, maka diperlukan unsur hara tambahan yang dapat diberikan melalui pemupukan. Pupuk adalah input yang tidak bisa dilepaskan pada pertanian modern, khususnya dengan adanya teknik budidaya baru dan kultivar yang produksinya tinggi. Penurunan kesuburan tanah telah meningkatkan kebutuhan input agar produktivitas terjaga. Penggunaan pupuk yang intensif khususnya pupuk kimia diyakini telah mempunyai efek merusak tanah, air dan lingkungan. Penggunaan pupuk kimia secara terus menerus dapat menurunkan produktivitas lahan melalui penurunan kandungan bahan organik, terhambatnya aktivitas mikroorganisme tanah dan berkurangnya kapasitas suplai hara tertentu (Sukartono, 1998).

Untuk menggunakan pupuk secara efisien terdapat beberapa faktor antara lain pemilihan pupuk yang tepat dalam bentuk, jumlah dan sumber pupuk. Pemberian pupuk harus diberikan secara berimbang dan sesuai dengan kebutuhan tanaman agar mendapatkan hasil yang optimal. Sama seperti tanaman lainnya, hanjeli memerlukan unsur hara yang cukup. Ketersediaan unsur hara merupakan salah satu factor yang dapat mempengaruhi tingkat produksi tanaman, hal ini dapat terpenuhi apabila dosis yang berikan tepat (Sarief, 1995).

Pupuk anorganik adalah pupuk yang biasa diberikan, terutama pupuk yang dapat meningkatkan ketersediaan N, P, dan K. pupuk anorganik memiliki kekurangan yaitu terbatasnya unsur hara yang tersedia dan tidak terdapatnya unsur hara mikro. Menurut Sarief (1995) jumlah unsur hara yang dibutuhkan tanaman adalah 16 jenis yaitu, $\mathrm{C}$, $\mathrm{H}, \mathrm{O}, \mathrm{N}, \mathrm{P}, \mathrm{K}, \mathrm{Ca}, \mathrm{Mg}, \mathrm{S}, \mathrm{Fe}, \mathrm{B}, \mathrm{Mn}, \mathrm{Cu}, \mathrm{Zn}, \mathrm{Mo}$, dan $\mathrm{Cl}$.

Untuk mengatasi kekurangan pupuk anorganik dapat dilakukan upaya yaitu dengan menambahkan pupuk organik. Penggunaan pupuk organik sebagai pupuk tambahan memberikan keuntungan antara lain dapat menyediakan semua unsur hara, baik makro maupun mikro dalam jumlah seimbang. Residu bahan organik akan berpengaruh pada tanaman berikutnya dan juga mempertahankan produktivitas tanah (Parnata, 2010).

Pupuk organik umunya adalah pupuk lengkap karena mengandung unsur makro dan mikro meskipun jumlahnya sedikit (Prihmantoro, 1996). Pupuk organik bersumber dari berbagai macam bahan, dengan kandungan 
kimia dan karakteristik fisik yang beragam sehingga efek dari pupuk organik terhadap lahan dan tanaman beragam. Selain itu, pupuk organik memiliki peranan yang cukup besar dalam perbaikan sifat fisika, kimia, dan biologi tanah serta terhadap lingkungan. Penggunaan pupuk organik alam yang dapat digunakan untuk membantu mengatasi masalah produksi pertanian yaitu pupuk organik cair.

Pupuk organik cair (POC) pada umumnya adalah ekstrak bahan organik yang telah dilarutkan dengan pelarut. POC memiliki kandungan unsur hara makro dan mikro yang dapat memenuhi kebutuhan unsur hara terutama unsur hara mikro yang terbatas ketersediaannya di dalam tanah sehingga diharapkan pertumbuhan dan hasil tanaman dapat meningkat. POC pemantap tanah "Soil Conditioner", yaitu senyawa asam humat dan fulvat yang merupakan sisa pembakaran bahan organik berkadar lignin tinggi sehingga relatif efisien terhadap pelapukan dan berperan penting dalam proses agregasi dan retensi hara sehingga tanah menjadi gembur, serta mencegah kehilangan hara melalui pencucian (Simarmata, 1999). Menurut hasil penelitian Novi Arifianty (2009), terdapat pengaruh kombinasi pupuk NPK dan POC pada seluruh variabel pengataman utama pada padi, yaitu tinggi tanaman pada 16 MST, indeks luas daun, jumlah anakan perumpun, jumlah malai per rumpun, bobot gabah kering per rumpun, dan per hekar, indeks panen, dan nisbah pupus akar.

Pupuk organik cair yang diharapkan dapat digunakan untuk meningkatkan produktivitas adalah pupuk organik cair Bio Sugih. Pupuk Organik cair Bio Sugih merupakan pupuk organik cair yang dapat memperbaiki dan meyuburkan tanah, mempercepat pertumbuha tanaman, dan meningkatkan produktivitas tanaman. Pupuk ini juga dapat meningkatkan daya tahan tanaman terhadap penyakit yang disebabkan oleh cendawan, membuat penyerapan hara lebih efektif dan mebuat bunga dan buah menjadi tahan akan kerontokan. Anjuran Bio Sugih yang digunakan untuk memupuk tanaman pangan adalah 15 liter per hektar, dengan konsentrasi 2cc/1 air (Parnata, 2010). Aplikasi bahan organik ke dalam tanah merupakan cara yang efektif untuk memelihara kesuburan tanah. Selama proses dekomposisi, bahan organik dapat mensuplai unsur hara makro dan mikro dalam jumlah yang cukup bagi tanaman (Juang, 1992).

\section{Bahan dan Metode}

Percobaan dilaksanakan di Desa Pasir Biru, Kecamatan Rancakalong, Kabupaten Sumedang. Lokasi tempat percobaan memiliki ketinggian \pm 800 mdpl dan termasuk tipe curah hujan B2 menurut klasifikasi Oldeman. Waktu pelaksanaan dimulai pada bulan Desember 2015 sampai Mei 2016.

Bahan-bahan yang digunakan dalam penelitian ini adalah benih hanjeli, NPK majemuk, urea, furadan, pupuk organik cair, dan kompos. Alat-alat yang digunakan dalam penelitian ini adalah cangkul, embrat/gembor, sprayer, meteran untuk mengukur tinggi tanaman, alat tulis, dan label sebagai tanda perlakuan dan ulangan.

Rancangan percobaan yang digunakan adalah Rancangan Acak Kelompok (RAK) yang terdiri dari 9 perlakuan. Jarak tanam yang dipergunakan adalah $50 \times 50 \mathrm{~cm}, 75 \times 50 \mathrm{~cm}$, dan $100 \times 50 \mathrm{~cm}$. Dosis pupuk organik cair yang digunakan adalah $0 \mathrm{~L} / \mathrm{ha}, 15 \mathrm{~L} /$ ha dan $30 \mathrm{~L} / \mathrm{ha}$.

\section{Hasil dan Pembahasan}

\section{Pengamatan Penunjang}

Analisis Tanah Awal. Tanah percobaan ini memiliki tekstur tanah liat yang memiliki kandungan pasir $25 \%$, debu $34 \%$, dan liat $41 \%$. Informasi kandungan kimia tanah yang diperoleh diantaranya nilai kemasaman/pH yaitu 5,45 tergolong kedalam tanah masam. Kejenuhan basa pada tanah penelitian ini adalah $25,75 \%$, termasuk ke dalam kriteria rendah. Kandungan C-organik yang terdapat pada tanah ini adalah 2,28 \%, nilai ini termasuk ke dalam kriteria sedang.

Nilai kapasitas tukar kation tanah percobaan ini yaitu $24,96 \mathrm{cmol} \mathrm{kg}^{-1}$, termasuk kedalam kriteria sedang. Kandungan kationkation dapat ditukar seperti $\mathrm{K}$ tinggi $(0,65 \mathrm{cmol}$ $\left.\mathrm{kg}^{-1}\right)$, Na rendah $\left(0,16 \mathrm{cmol} \mathrm{kg}^{-1}\right)$, Ca rendah $(2,20$ cmol kg-1) dan $\mathrm{Mg}\left(3,41 \mathrm{cmol} \mathrm{\textrm {kg } ^ { - 1 } )}\right.$ yang tergolong kedalam kriteria tinggi. Kandungan unsur hara $\mathrm{N}$ sebesar 0,16 yang tergolong rendah, $\mathrm{P}$ sebesar $102,29 \mathrm{mg} / 100 \mathrm{~g}$ yang termasuk sangat tinggi, dan $\mathrm{K}$ sebesar 26,67 yang termasuk sedang.

Berdasarkan analisis tanah tersebut dapat disimpulkan bahwa secara keseluruhan tanah pada lahan percobaan ini mempunyai sifat fisik dan kimia yang baik untuk tanaman hanjeli. 
Data Iklim. Curah hujan selama percobaan berkisar antara 249,8 - 518,2 mm/bulan. Suhu ratarata bulanan berkisar antara $22,8-23,5^{\circ} \mathrm{C}$, dengan suhu minimum yaitu $22,8{ }^{\circ} \mathrm{C}$ yang terjadi pada bulan Desember. Bulan Maret 2016 memiliki suhu rata-rata tertinggi yaitu $23,5^{\circ}$. Hanjeli dapat beradaptasi pada daerah tropik dan juga daerah kering dengan suhu sekitar $25{ }^{\circ} \mathrm{C}$ sampai $35{ }^{\circ} \mathrm{C}$ (Grubben dan Partohardjono, 1996).

Kelembaban udara selama percobaan berkisar antara 74,96 - 77,65\%. Kelembaban minimum yaitu $74,96 \%$ yang terjadi pada bulan Desember. Bulan Maret 2016 memiliki kelembaban rata-rata tertinggi yaitu $77,65 \%$. Data intensitas cahaya terlampir pada. Intensitas cahaya selama percobaan berkisar antara 303 - 509.33 Lux.

Gulma yang Tumbuh Selama Percobaan. Gulma yang tumbuh selama percobaan adalah babadotan (Ageratum conizoides) dan Calincingan (Oxalis latifolia). Pengendalian gulma dilakukan secara mekanis yaitu dengan cara mencabut gulma pada saat tanaman berumur 3 MST dan 8 MST. Pembumbunan dilakukan bersamaan dengan penyiangan kedua juga dengan tujuan memperkokoh perakaran tanaman.

Serangan Hama Selama Percobaan. Hama yang menyerang tanaman hanjeli adalah uret (Lepidiota stigma), ulat jengkal (Argyrogramma signata) dan ulat penggulung daun (Cnaphalo-crosis medinalis).Ulat jengkal dan ulat peng-gulung daun memakan daun dan menyebabkan luka berwarna kekuningan kemudian menge-ring dan menjadi coklat.Hama ini menyerang pada saat tanaman berumur 5 MST. Uret memakan akar-akar tanaman hanjeli yang membuat hanjeli layu dan menguning seperti kekurangan air, tetapi tingkat serangan hama yang ditemukan tidak mencapai 5 $\%$ sehingga tidak dilakukan tindakan pengen- dalian. Penyakit yang menyerang tanaman hanjeli tidak ditemukan dalam percobaan ini.

\section{Pengamatan Utama: Komponen Pertumbuhan}

Tinggi Tanaman. Dari data hasil analisis statistik pengaruh kombinasi jarak tanam dengan dosis pupuk organik cair terlihat bahwa tinggi tanaman menunjukan tidak adanya pengaruh kombinasi jarak tanam dengan dosis pupuk organik cair pada setiap minggunya.

Tinggi tanaman selama fase vegetatif dipengaruhi oleh penyerapan unsur hara nitrogen, fosfor, kalium, dan besi. Menurut Humpreys (1978) dikutip Hasbi dan Ana Rochana Tarmidi (1995) unsur nitrogen yang tersedia akan dimanfaatkan terlebih dahulu untuk pertumbuhan vegetatif, antara lain untuk penambahan tinggi tanaman dan penambahan jumlah daun.

Biomassa Tanaman dan Indeks Luas Daun. Hasil uji F pada taraf $5 \%$ menunjukkan adanya pengaruh antara kombinasi jarak tanam dengan dosis pupuk organik cair terhadap biomassa tanaman. Kombinasi jarak tanam 100 $\mathrm{cm} \times 50 \mathrm{~cm}$ dengan dosis $0 \mathrm{~L} / \mathrm{Ha}$ pupuk organik cair memberikan pengaruh terbaik tetapi tidak berbeda dengan kombinasi jarak tanam $75 \mathrm{~cm} \mathrm{x}$ $50 \mathrm{~cm}$ dengan dosis $30 \mathrm{~L} / \mathrm{Ha}$ pupuk organik cair. Menurut Gardner dkk. (1991) menya-takan bahwa faktor yang mempengaruhi bobot kering total yaitu kemampuan daun untuk menyerap radiasi matahari dan efisiensi peman-faatan energi tersebut untuk memfiksasi $\mathrm{CO}_{2}$.

Hal ini disebabkan karena tercukupinya unsur hara makro dan mikro seperti Mo dan Boron melalui pemberian pupuk organik cair. Menurut Aisyah D. S. (2008), Mo berfungsi dalam fiksasi $\mathrm{N}$ dan Boron berfungsi dalam perkembangan sel-sel baru jaringan meristematik.

Tabel 1. Pengaruh Kombinasi Jarak Tanam dengan dosis Pupuk Organik Cair terhadap Tinggi Tanaman.

\begin{tabular}{|c|c|c|c|c|}
\hline \multirow{2}{*}{ Perlakuan } & \multicolumn{4}{|c|}{ "Tinggi Tanaman $(\mathrm{cm})$} \\
\hline & $5 \mathrm{MST}$ & $8 \mathrm{MST}$ & $11 \mathrm{MST}$ & $14 \mathrm{MST}$ \\
\hline $50 \times 50 \mathrm{~cm}+0 \mathrm{~L} \mathrm{ha}^{-1}$ & $51,11 \mathrm{a}$ & $93,44 \mathrm{a}$ & $184,56 \mathrm{a}$ & $229,22 \mathrm{a}$ \\
\hline $50 \times 50 \mathrm{~cm}+15 \mathrm{~L} \mathrm{ha}^{-1}$ & $52,44 \mathrm{a}$ & $104,89 \mathrm{a}$ & 194,67 a & $245,66 \mathrm{a}$ \\
\hline $50 \times 50 \mathrm{~cm}+30 \mathrm{~L} \mathrm{ha}^{-1}$ & $48,11 \mathrm{a}$ & $96,11 \mathrm{a}$ & $180,44 \mathrm{a}$ & $209,33 \mathrm{a}$ \\
\hline $75 \times 50 \mathrm{~cm}+0 \mathrm{~L} \mathrm{ha}^{-}$ & 33,33 a & $71,67 \mathrm{a}$ & $144,00 \mathrm{a}$ & $188,56 \mathrm{a}$ \\
\hline $75 \times 50 \mathrm{~cm}+15 \mathrm{~L} \mathrm{ha}^{-}$ & $42,33 \mathrm{a}$ & $83,56 \mathrm{a}$ & $144,45 \mathrm{a}$ & $215,56 \mathrm{a}$ \\
\hline $75 \times 50 \mathrm{~cm}+30 \mathrm{~L} \mathrm{ha}^{-1}$ & $38,78 \mathrm{a}$ & $82,00 \mathrm{a}$ & 159,66 a & $227,92 \mathrm{a}$ \\
\hline $100 \times 50 \mathrm{~cm}+0 \mathrm{~L} \mathrm{ha}^{-1}$ & $35,33 \mathrm{a}$ & $70,11 \mathrm{a}$ & 143,11 a & $215,67 \mathrm{a}$ \\
\hline $100 \times 50 \mathrm{~cm}+15 \mathrm{~L} \mathrm{ha}^{-1}$ & $30,78 \mathrm{a}$ & $76,56 \mathrm{a}$ & 147,33 a & $238,78 \mathrm{a}$ \\
\hline $100 \times 50 \mathrm{~cm}+30 \mathrm{~L} \mathrm{ha}^{-1}$ & $36,44 \mathrm{a}$ & $80,22 \mathrm{a}$ & $145,34 \mathrm{a}$ & $206,56 \mathrm{a}$ \\
\hline
\end{tabular}

Keterangan : Nilai rataan yang diikuti oleh huruf yang sama tidak berbeda nyata menurut uji Duncan pada taraf $5 \%$ 
Tabel 2. Pengaruh Kombinasi Jarak Tanam dengan dosis Pupuk Organik Cari terhadap Biomassa (g) dan Indeks Luas Daun (ILD).

\begin{tabular}{lcc}
\hline \hline Perlakuan & Biomassa (g) & ILD \\
\hline $50 \times 50 \mathrm{~cm}+0 \mathrm{~L} \mathrm{ha}^{-1}$ & $623,66 \mathrm{~b}$ & $4,53 \mathrm{~b}$ \\
$50 \times 50 \mathrm{~cm}+15 \mathrm{~L} \mathrm{ha}^{-1}$ & $745,08 \mathrm{~b}$ & $6,57 \mathrm{a}$ \\
$50 \times 50 \mathrm{~cm}+30 \mathrm{~L} \mathrm{ha}^{-1}$ & $659,69 \mathrm{~b}$ & $5,39 \mathrm{~b}$ \\
$75 \times 50 \mathrm{~cm}+0 \mathrm{~L} \mathrm{ha}^{-}$ & $540,63 \mathrm{~b}$ & $5,82 \mathrm{a}$ \\
$75 \times 50 \mathrm{~cm}+15 \mathrm{~L} \mathrm{ha}^{-}$ & $544,48 \mathrm{~b}$ & $4,47 \mathrm{~b}$ \\
$75 \times 50 \mathrm{~cm}+30 \mathrm{~L} \mathrm{ha}^{-1}$ & $1490,64 \mathrm{a}$ & $6,96 \mathrm{a}$ \\
$100 \times 50 \mathrm{~cm}+0 \mathrm{~L} \mathrm{ha}^{-1}$ & $1705,66 \mathrm{a}$ & $7,77 \mathrm{a}$ \\
$100 \times 50 \mathrm{~cm}+15 \mathrm{~L} \mathrm{ha}^{-1}$ & $856,02 \mathrm{a}$ & $3,08 \mathrm{~b}$ \\
$100 \times 50 \mathrm{~cm}+30 \mathrm{~L} \mathrm{ha}^{-1}$ & $316,89 \mathrm{~b}$ & $4,63 \mathrm{~b}$ \\
\hline \hline
\end{tabular}

Keterangan : Nilai rataan yang diikuti oleh huruf yang sama tidak berbeda nyata menurut uji Duncan pada taraf $5 \%$

Indeks luas daun tertinggi terdapat pada perlakuan Jarak tanam $100 \mathrm{~cm} \times 50 \mathrm{~cm}+0 \mathrm{~L} \mathrm{ha}^{-1}$ pupuk organik cair namun tidak berbeda nyata dengan perlakuan jarak tanam $75 \mathrm{~cm} \times 50 \mathrm{~cm}$ dan $50 \mathrm{~cm} \times 50 \mathrm{~cm}$. Menurut Goldsworthty dan Fischer (1992) dalam Agrita (2012) Faktor yang mempengaruhi besarnya indeks luas daun antara lain adalah jarak tanam dan penyediaan unsur hara nitrogen.

Nisbah Pupus Akar. Nisbah pupus akar yang ideal bagi tanamanpangan adalah 3 (Salibury dan Ross, 1955). Nilai rata-rata yang didapatkan pada saat percobaan adalah 2,93. Hal ini menunjukkan bahwa pertumbuhan tanaman terarah merata sehingga penyerapan air dan usur hara optimal.Menurut Gardner, dkk (1991) bahwa semakin besar bobot kering akar, menggambarkan akar berada dalam kondisi yang optimal dalam penyerapan air dan unsur hara.
Tabel 3. Pengaruh Kombinasi Jarak Tanam dan Pupuk Organik Cair terhadap Nisbah Pupus Akar.

\begin{tabular}{lc}
\hline \hline Perlakuan & Nisbah Pupus Akar \\
\hline $50 \times 50 \mathrm{~cm}+0 \mathrm{~L} \mathrm{ha}^{-1}$ & $2,40 \mathrm{a}$ \\
$50 \times 50 \mathrm{~cm}+15 \mathrm{~L} \mathrm{ha}^{-1}$ & $2,51 \mathrm{a}$ \\
$50 \times 50 \mathrm{~cm}+30 \mathrm{~L} \mathrm{ha}^{-1}$ & $2,59 \mathrm{a}$ \\
$75 \times 50 \mathrm{~cm}+0 \mathrm{~L} \mathrm{ha}^{-}$ & $2,21 \mathrm{a}$ \\
$75 \times 50 \mathrm{~cm}+15 \mathrm{~L} \mathrm{ha}^{-}$ & $3,42 \mathrm{a}$ \\
$75 \times 50 \mathrm{~cm}+30 \mathrm{~L} \mathrm{ha}^{-1}$ & $2,47 \mathrm{a}$ \\
$100 \times 50 \mathrm{~cm}+0 \mathrm{~L} \mathrm{ha}^{-1}$ & $2,71 \mathrm{a}$ \\
$100 \times 50 \mathrm{~cm}+15 \mathrm{~L} \mathrm{ha}^{-1}$ & $4,08 \mathrm{a}$ \\
$100 \times 50 \mathrm{~cm}+30 \mathrm{~L} \mathrm{ha}^{-1}$ & $3,99 \mathrm{a}$ \\
\hline \hline
\end{tabular}

Keterangan : Nilai rataan yang diikuti oleh huruf yang sama tidak berbeda nyata menurut uji Duncan pada taraf $5 \%$

Jumlah Anakan Per Rumpun dan Jumlah Srisip Per Rumpun. Jumlah anakan selama fase vegetatif dipengaruhi oleh penyerapan unsur hara nitrogen, fosfor, kalium, dan besi. Tabel 4 menunjukkan tidak adanya pengaruh kombinasi jarak tanam dengan dosis pupuk organik cair pada setiap perlakuan. Hal ini diduga karena curah hujan yang cukup dan unsur hara yang tercukupi pada awal fase pertumbuhan, sehingga kebutuhan semua tanaman tercukupi dan membuat jumlah anakan yang dihasilkan relatif sama.

Unsur nitrogen banyak diperlukan pada fase vegetatif untuk memperbanyak jumlah srisip.Fosfor dan kalium juga diperlukan dalam pembentukan srisip. Hal ini diduga karena curah hujan yang cukup dan unsur hara yang tercukupi pada awal fase pertumbuhan, sehingga kebutuhan semua tanaman tercukupi dan membuat jumlah srisip yang dihasilkan relatif sama.

Tabel 4. Pengaruh Kombinasi Jarak Tanam dengan dosis Pupuk Organik Cair terhadap Jumlah Anakan Per Rumpun dan Jumlah Srisip Per Rumpun.

\begin{tabular}{|c|c|c|c|c|c|}
\hline \multirow{2}{*}{ Perlakuan } & \multicolumn{4}{|c|}{ Anakan } & \multirow{2}{*}{$\begin{array}{l}\text { Srisip Per } \\
\text { Rumpun }\end{array}$} \\
\hline & 5 MST & $8 \mathrm{MST}$ & $11 \mathrm{MST}$ & 14 MST & \\
\hline $50 \times 50 \mathrm{~cm}+0 \mathrm{~L} \mathrm{ha}^{-1}$ & $4,56 \mathrm{a}$ & $7,44 \mathrm{a}$ & $7,78 \mathrm{a}$ & $9,58 \mathrm{a}$ & $83,67 \mathrm{a}$ \\
\hline $50 \times 50 \mathrm{~cm}+15 \mathrm{~L} \mathrm{ha}^{-1}$ & 4,89 a & $11,56 \mathrm{a}$ & $11,45 \mathrm{a}$ & $12,11 \mathrm{a}$ & 78,33 a \\
\hline $50 \times 50 \mathrm{~cm}+30 \mathrm{~L} \mathrm{ha}^{-1}$ & $3,33 \mathrm{a}$ & $6,89 \mathrm{a}$ & $7,44 \mathrm{a}$ & 10,17 a & $88,50 \mathrm{a}$ \\
\hline $75 \times 50 \mathrm{~cm}+0 \mathrm{~L} \mathrm{ha}^{-}$ & $2,78 \mathrm{a}$ & $6,33 a$ & $9,11 \mathrm{a}$ & $13,78 \mathrm{a}$ & 120,33 a \\
\hline $75 \times 50 \mathrm{~cm}+15 \mathrm{~L} \mathrm{ha}^{-}$ & $4,67 \mathrm{a}$ & $8,22 \mathrm{a}$ & $9,78 \mathrm{a}$ & $11,14 \mathrm{a}$ & $94,00 \mathrm{a}$ \\
\hline $75 \times 50 \mathrm{~cm}+30 \mathrm{~L} \mathrm{ha}^{-1}$ & $3,78 \mathrm{a}$ & 8,89 a & $12,00 \mathrm{a}$ & $12,42 \mathrm{a}$ & $138,78 \mathrm{a}$ \\
\hline $100 \times 50 \mathrm{~cm}+0 \mathrm{~L} \mathrm{ha}^{-1}$ & $2,78 \mathrm{a}$ & $6,34 \mathrm{a}$ & $8,00 \mathrm{a}$ & $9,44 \mathrm{a}$ & $81,22 \mathrm{a}$ \\
\hline $100 \times 50 \mathrm{~cm}+15 \mathrm{~L} \mathrm{ha}^{-1}$ & $2,00 \mathrm{a}$ & $5,55 \mathrm{a}$ & $8,55 \mathrm{a}$ & $10,70 \mathrm{a}$ & 85,55 a \\
\hline $100 \times 50 \mathrm{~cm}+30 \mathrm{~L} \mathrm{ha}^{-1}$ & $4,00 \mathrm{a}$ & $8,00 \mathrm{a}$ & $10,11 \mathrm{a}$ & $14,89 \mathrm{a}$ & $144,22 \mathrm{a}$ \\
\hline
\end{tabular}

Keterangan : Nilai rataan yang diikuti oleh huruf yang sama tidak berbeda nyata menurut uji Duncan pada taraf $5 \%$ 


\section{Komponen Hasil}

Jumlah Malai Per Rumpun. Berdasarkan Tabel 5 menunjukan tidak adanya pengaruh kombinasi jarak tanam dengan dosis pupuk organik cair terhadap jumlah malai per rumpun. Hal ini terjadi karena jumlah anakan yang terbentuk tidak semua memproduksi malai. Produksi malai pada tanaman hanjeli dipengaruhi oleh banyak hal, terutama ketersediaan unsur hara.

Menurut Didiek Setio Budi (1998) dalam Novi Arivianty (2011), kemampuan tanaman menghasilkan malai ditentukan oleh banyaknya anakan serta faktor status air tanah selama masa vegetatif.

Tabel 5. Pengaruh Kombinasi Jarak Tanam dengan dosis Pupuk Organik Cair Terhadap Jumlah Malai Per Rumpun pada Umur 23 MST

\begin{tabular}{lc}
\hline \multicolumn{1}{c}{ Perlakuan } & Malai Per Rumpun \\
\hline $50 \times 50 \mathrm{~cm}+0 \mathrm{~L} \mathrm{ha}^{-1}$ & $126,08 \mathrm{a}$ \\
$50 \times 50 \mathrm{~cm}+15 \mathrm{~L} \mathrm{ha}^{-1}$ & $184,67 \mathrm{a}$ \\
$50 \times 50 \mathrm{~cm}+30 \mathrm{~L} \mathrm{ha}^{-1}$ & $145,61 \mathrm{a}$ \\
$75 \times 50 \mathrm{~cm}+0 \mathrm{~L} \mathrm{ha}^{-}$ & $168,89 \mathrm{a}$ \\
$75 \times 50 \mathrm{~cm}+15 \mathrm{~L} \mathrm{ha}^{-}$ & $168,39 \mathrm{a}$ \\
$75 \times 50 \mathrm{~cm}+30 \mathrm{~L} \mathrm{ha}^{-1}$ & $168,89 \mathrm{a}$ \\
$100 \times 50 \mathrm{~cm}+0 \mathrm{~L} \mathrm{ha}^{-1}$ & $155,00 \mathrm{a}$ \\
$100 \times 50 \mathrm{~cm}+15 \mathrm{~L} \mathrm{ha}^{-1}$ & $197,81 \mathrm{a}$ \\
$100 \times 50 \mathrm{~cm}+30 \mathrm{~L} \mathrm{ha}^{-1}$ & $187,56 \mathrm{a}$ \\
\hline \hline
\end{tabular}

Keterangan : Nilai rataan yang diikuti oleh huruf yang sama tidak berbeda nyata menurut uji

Duncan pada taraf $5 \%$

Tabel 6 menunjukan adanya pengaruh kombinasi jarak tanam dengan dosis pupuk organik cair terhadap bobot biji per petak dan bobot biji per hektar, dimana perlakuan dengan jarak tanam $50 \mathrm{~cm} \times 50 \mathrm{~cm}+30 \mathrm{~L} \mathrm{ha}^{-1}$ pupuk organik cair memberikan pengaruh terbaik.
Bobot biji per petak dan per hektar pada perlakuan tersebut adalah $11.10 \mathrm{~kg} /$ petak dan 9.72 ton/ha.Hal ini disebabkan karena pupuk organik cair memberikan tambahan unsur P dan $\mathrm{K}$ kepada tanaman, sehingga membuat bobot biji per rumpun tanaman hanjeli tinggi.

Tabel 6 menunjukkan tidak adanya pengaruh kombinasi jarak tanam dan pupuk organik cair terhadap bobot 100 biji. Hal ini diduga karena benih hanjeli yang digunakan sama. Masdar (2005) menjelaskan bahwa bobot biji tidak dipengaruhi oleh jarak tanam dan pemupukan, namun dikarenakan faktor genetik tanaman itu sendiri.

Tabel 7. Pengaruh Kombinasi Jarak Tanam dengan dosis Pupuk Organik Cair terhadap Indeks Panen.

\begin{tabular}{lc}
\hline \hline Perlakuan & Indeks Panen \\
\hline $50 \times 50 \mathrm{~cm}+0 \mathrm{~L} \mathrm{ha}^{-1}$ & $0,41 \mathrm{a}$ \\
$50 \times 50 \mathrm{~cm}+15 \mathrm{~L} \mathrm{ha}^{-1}$ & $0,21 \mathrm{~b}$ \\
$50 \times 50 \mathrm{~cm}+30 \mathrm{~L} \mathrm{ha}^{-1}$ & $0,53 \mathrm{a}$ \\
$75 \times 50 \mathrm{~cm}+0 \mathrm{~L} \mathrm{ha}^{-}$ & $0,48 \mathrm{a}$ \\
$75 \times 50 \mathrm{~cm}+15 \mathrm{~L} \mathrm{ha}^{-}$ & $0,41 \mathrm{a}$ \\
$75 \times 50 \mathrm{~cm}+30 \mathrm{~L} \mathrm{ha}^{-1}$ & $0,28 \mathrm{~b}$ \\
$100 \times 50 \mathrm{~cm}+0 \mathrm{~L} \mathrm{ha}^{-1}$ & $0,20 \mathrm{~b}$ \\
$100 \times 50 \mathrm{~cm}+15 \mathrm{~L} \mathrm{ha}^{-1}$ & $0,55 \mathrm{a}$ \\
$100 \times 50 \mathrm{~cm}+30 \mathrm{~L} \mathrm{ha}^{-1}$ & $0,32 \mathrm{~b}$ \\
\hline
\end{tabular}

Keterangan : Nilai rataan yang diikuti oleh huruf yang sama tidak berbeda nyata menurut uji Duncan pada taraf $5 \%$

Indeks Panen. Tabel 7 menunjukkan kombinasi jarak tanam dengan dosis pupuk organik cair memberikan pengaruh terhadapa indeks panen. Indeks panen tersebut menunjukkan dengan Jarak tanam $100 \mathrm{~cm} \times 50 \mathrm{~cm}+15 \mathrm{~L} \mathrm{ha}^{-1}$ Pupuk Organik Cair dapat memberikan hasil biji yang tinggi. Hal ini dikarenankan bobot biji per

Tabel 6. Pengaruh Kombinasi Jarak Tanam dengan dosis Pupuk Organik Cair terhadap Bobot Biji Per Rumpun, Bobot Biji Per Petak, Bobot Biji Per Hektar, dan Bobot 100 Biji

\begin{tabular}{lcccc}
\hline \hline Perlakuan & $\begin{array}{c}\text { Bobot Biji Per } \\
\text { Rumpun (g) }\end{array}$ & $\begin{array}{c}\text { Bobot Biji Per } \\
\text { Petak (kg) }\end{array}$ & $\begin{array}{c}\text { Bobot Biji Per } \\
\text { Hektar (ton) }\end{array}$ & Bobot 100 Biji \\
\hline $50 \times 50 \mathrm{~cm}+0 \mathrm{~L} \mathrm{ha}^{-1}$ & $256,00 \mathrm{~b}$ & $8,19 \mathrm{~b}$ & 7,16 & $11,83 \mathrm{a}$ \\
$50 \times 50 \mathrm{~cm}+15 \mathrm{~L} \mathrm{ha}^{-1}$ & $156,00 \mathrm{~b}$ & $4,99 \mathrm{c}$ & 4,36 & $13,30 \mathrm{a}$ \\
$50 \times 50 \mathrm{~cm}+30 \mathrm{~L} \mathrm{ha}^{-1}$ & $347,00 \mathrm{a}$ & $11,10 \mathrm{a}$ & 9,72 & $12,67 \mathrm{a}$ \\
$75 \times 50 \mathrm{~cm}+0 \mathrm{~L} \mathrm{ha}^{-}$ & $263,00 \mathrm{~b}$ & $5,26 \mathrm{c}$ & 4,91 & $12,83 \mathrm{a}$ \\
$75 \times 50 \mathrm{~cm}+15 \mathrm{~L} \mathrm{ha}^{-}$ & $225,67 \mathrm{~b}$ & $4,51 \mathrm{c}$ & 4,21 & 10,48 \\
$75 \times 50 \mathrm{~cm}+30 \mathrm{~L} \mathrm{ha}^{-1}$ & $415,00 \mathrm{a}$ & $8,30 \mathrm{~b}$ & 7,24 & $14,19 \mathrm{a}$ \\
$100 \times 50 \mathrm{~cm}+0 \mathrm{~L} \mathrm{ha}^{-1}$ & $341,00 \mathrm{a}$ & $5,46 \mathrm{c}$ & 4,77 & $13,49 \mathrm{a}$ \\
$100 \times 50 \mathrm{~cm}+15 \mathrm{~L} \mathrm{ha}^{-1}$ & $472,33 \mathrm{a}$ & $7,56 \mathrm{~b}$ & 5,23 & $13,93 \mathrm{a}$ \\
$100 \times 50 \mathrm{~cm}+30 \mathrm{~L} \mathrm{ha}^{-1}$ & $101,00 \mathrm{~b}$ & $1,62 \mathrm{~d}$ & 1,42 & $12,43 \mathrm{a}$ \\
\hline \hline
\end{tabular}

Keterangan : Nilai rataan yang diikuti oleh huruf yang sama tidak berbeda nyata menurut uji Duncan pada taraf $5 \%$. Bobot biji per hektar tidak diuji statistic sehingga tidak memiliki notasi. 
rumpun yang dihasilkan dari perlakuan memiliki nilai paling besar.Menurut Donald dan Hamblin (1976) dalam Gardner F.P., dkk, 1991) indeks panen menunjukkan perbandingan distribusi hasil asimilasi antara biomassa ekonomis dengan biomassa keseluruhan.

\section{Kesimpulan}

1. Kombinasi jarak tanam dengan dosis pupuk organik cair mempengaruhi biomassa, ILD, bobot biji per rumpun, bobot biji per petak, bobot biji per hektar, dan indeks panen tetapi tidak mempengaruhi terhadap variabel pengamatan lainnya termasuk tinggi tanaman dan jumlah anakan.

2. Kombinasi jarak tanam $50 \mathrm{~cm} \times 50 \mathrm{~cm}$ dan dosis pupuk organik cair $30 \mathrm{~L} /$ ha memberikan pertumbuhan dan hasil terbaik pada tanaman hanjeli yaitu pada bobot biji per petak dengan hasil $11,10 \mathrm{~kg}$ per petak dan bobot biji per hektar dengan hasil 9,72 ton per hektar.

Perlu adanya penelitian lanjutan, dengan mengurangi pupuk kandang dan pupuk anorganik agar dapat dilihat pengaruh dari pupuk organik cair tersebut tetapi tidak menghilangkan fungsi pupuk kandang dan anorganik sebagai pupuk dasar.

\section{Daftar Pustaka}

Aisyah D.S., dkk. 2008. Pupuk dan Pemupukan. Divisi Penerbitan LPM Unpad. (Unpad Press) Bandung.

Arifianty, N. 2009. Pengurangan Dosis Pupuk N, $\mathrm{P}, \mathrm{K}$ dengan Pupuk Organik Cair terhadap Pertumbuhan dan Hasil Tanaman Padi Sawah (Oryza sativa L.) Varietas Ciherang. Skripsi. Faperta Unpad (tidak dipublikasikan).

Gardner, F. P., R. B. Pearce and R. L. Mitchell. 1991. Fisiologi Tanaman Budidaya. Terjemahan Herawati Susilo dan Subiyanto. Penerbit UI Press. Jakarta. 424 Hal.

Goldsworthy, P.R. dan N.M. Fisher. 1992. Fisiologi Tanaman Budidaya Tropik (Terj. Tohari). Gama Univ. Press. Yogyakarta.

Gruben, G. J. H. and S. Partohardjono. 1996. Plant Resourcees of South - East Asia No.
10 Cereals. Prosea. Bogor.

Juang T, C. 1992. Effects of Combined Compost Chemical Fertilizer Application on Soil Fertility and Crop Yield Under Rice - Corn Rotation. UPM Press. Malaysia.

Masdar. 2005. Interaksi Jarak Tanam dan Jumlah Bibit Per Titik Tanam pada Sistem Intensifikasi Padi Terhadap Pertumbuhan Vegetatif Tanaman. Akta Agrosia Ed. Khusus. (1): 92-98

Nurmala, T. dan Aep Wawan Irwan. 2007. Pangan Alternatif Berbasis Serealia Minor. Giratuna. Bandung.

Pederson and J.G. Lauer. 2003. Soybean Agronomic Response to Management System in The Upper. Midwest. Agronomy Journal.

Parnata, A. S. 2010. Meningkatkan Hasil Panen dengan Pupuk Organik. Agromedia Pustaka. Jakarta

Prihmantoro, H. 1996. Memupuk Tanaman Buah. PT Penebar Swadaya. Jakarta.

Rusdi, M. 1985. Proyek Penelitian Pengaruh Jarak Tanam dan Pemupukan Fosfor Terhadap Pertumbuhan dan Produksi Jagung yang ditanam Bersama dengan Centrosema pubescens. Fakultas Pertanian Universitas Hasanudin. (Tidak dipublikasikan)

Salisbury, F.B., C.W. Ross. 1995. Fisiologi Tumbuhan Dasar Jilid 2. Terjemahan dari: Plant Physiology. Penerjemah: Lukman D.R., Sumaryono. Bandung: ITB Press.

Sarief, H.E. Saifuddin. 1995. Kesuburan dan Pemupukan Tanah Pertanian. Pustaka Buana. Bandung.

Simarmata, T. 1999. Aplikasi Pupuk Majemuk Lengkap : Pupuk Unggulan Untuk Meningkatkan Efisiensi Pemupukan dan Produktivitas Lahan Menuju Pertanian Berkelanjutan (Sistainable Agriculture). Makalah Seminar di Kantor Dep. Koperasi Kab. Garut.

Sukartono. 1998. Dinamika C-tanah Akibat Penambahan Biochar pada Sistem Pertanaman Jagung di Lahan Kering Lombok Utara. Universitas Brawijaya.

Thomson, H. dan W. Kelly. 1987. Vegetable Crops. McGraw-Hill Books Co. Inc. London.

Tirtrapradja, H dan A.R. Tarmidi. 1995. Pengaruh Jarak Tanam dan Pemupukan Nitrogen Terhadap Produktivitass Biji dan Hijauan Tanaman Jali (Coix lacryma-jobi L.). Agrikultura Vol. 6 No. 1: 29-34. 